\title{
Design, modelling, energy and exergy analysis of a parabolic cooker
}

\author{
Anthony O. Onokwai a, *, Ugochukwu C. Okonkwo ${ }^{\text {b }}$, Christian O. Osueke ${ }^{\text {a }}$, \\ Christian E. Okafor ${ }^{b}$, Tajudeen M.A. Olayanju ${ }^{\text {a }}$, Samuel, O. Dahunsi ${ }^{a}$ \\ a Landmark University, Omu-Aran, Kwara State, Nigeria \\ ${ }^{\mathrm{b}}$ Nnamdi Azikiwe University, Awka, Anambra State, Nigeria
}

\section{A R T I C L E I N F O}

\section{Article history:}

Received 9 April 2018

Received in revised form 5 April 2019

Accepted 7 April 2019

Available online 24 April 2019

\section{Keywords:}

Design

Efficiency

Materials

Solar energy

Parabolic

\begin{abstract}
A B S T R A C T
A functional parabolic solar cooker was designed and constructed to serve as an alternate renewable source of energy for cooking and to also reduce the adverse effects of other sources of energy on the environment. The solar cooker was fabricated using cheap, locally sourced available materials in Nigeria. Experimental investigation was carried out on the produced model in Omu-Aran Metropolis, Kwara State, Nigeria in December 2016. Thereafter other investigations were carried out from January to December 2017 and lastly in January 2018 between the hours of 10:00 a.m. to 5:00 p.m. local time for both stagnation and sensible heating, using $2 \mathrm{~L}$ of water at every experiment. The average energy and exergy efficiencies of the parabolic cooker were about 39\% and $44 \%$ respectively. The instability of the energy efficiency occurred as a result of optical and thermal losses from the reflector and pot, as well as the varying environmental conditions. Mathematical expressions were used to calculate the theoretical values of energy and exergy efficiencies using Minitab, while the statistical analysis showed that there was no significant difference between the experimental and predicted results for exergy and energy efficiencies of both cookers at $\mathrm{p}>0.05$, this validated the design.
\end{abstract}

(c) 2019 Elsevier Ltd. All rights reserved.

\section{Introduction}

Solar energy is outstanding amongst other methods for reducing the utilization of non-renewable resources [1]. With solar energy, the sun's rays are utilized to heat homes through glass windows, cook food, charge battery, generate electricity, and heat water or different fluids [2]. Prior to the emergence of renewable energy, fossil fuels constitute the primary energy resource that has been used to power human technological advancement, since the industrial revolution. But there are consequences, for instance, studies show that the high volume of pollutants fossil fuels emissions are harmful to public health and environment [3,4,39], while the use of fuelwood not only causes deforestation but also loss of habitat for millions of species.

Furthermore, in the words of Gardner-Outlaw and Engelman [5] "The search for wood fuel consumes the time, energy and health of women and their children. As local wood supplies grow scarce, women risk spinal cord defect and uterine prolapsed from carrying heavy loads over longer distances. Girls are often requested not to

\footnotetext{
* Corresponding author.

E-mail address: onokwai.anthony@lmu.edu.ng (A.O. Onokwai).
}

attain classes in order to help their mothers gather wood for cooking, thereby depriving them of the attendant benefits of education. Where wood is unavailable, women cook with inefficient fuels such as animal dung or crop wastes, depriving livestock of fodder and soils of natural fertilizers. This endangers both the nutritional and respiratory health of women and their families." It has also been emphasized by the World Health Organization (WHO) that 1.6 million deaths per year are caused by indoor air pollution [6]. The dangerous indoor air pollution is not limited to rural dwellers utilizing fuelwood but extends to the majority of urban dwellers that utilize kerosene and gas for cooking. In as much as fossil fuel contributes a great deal to the world energy demand, yet the fear of depletion of fossil fuels due to the fast rate of consumption has provoked further development of these alternative energy sources, such as solar energy [7].

Okafor [8] conducted feasibility Study on the provision of solar energy in rural area using solar panel; this gave a viable direction for rural development, while this research focused on thermal energy for solar cooking. We initiated the research by considering the thermal performance of a solar cooker and the weather conditions in Nigeria. Firstly, The important of thermal performance indicators for solar cooker, obtained through exergy analysis was emphasized by Kumar et al. [9]; while the work of Hereza et al. [10] 
reviewed the principle, classification and parameters affecting the thermal performance of a solar cooker as well as energy and exergy analysis. Secondly, Osueke et al. [11] investigated the variation in weather conditions stemming from the variation in the amount of solar radiation incidents in the different geographical location in Nigeria; this had assisted in data analysis and the viability of the research which indicates an abundant solar radiant in Nigeria. Thereafter we considered some models.

Petela [12] modelled an exergy analysis of a simple solar parabolic cooker (SPC), of a cylindrical trough shape, the model allowed for theoretical estimation of the energy and exergy losses. In other to improve the performance of a parabolic cooker, Suhail [13], investigated the performance of an improved dual reflector foldable parabolic solar cooker, while, Harmim et al., [14] and Kaushik et al. [15], designed a novel solar box cooker integrated with compound parabolic concentrator. A comparative analysis of energy and exergy efficiency of box-type (SBC) and parabolic-type solar cookers (SPC) was carried out by Ozturk [16], and Pandey et al., [17]; the results of this study show that there was a significant difference between the results of energy and exergy analyses between the two, where SPC shows higher performance at the same time interval.

In all the literature reviewed, there is inadequate information on the maximizing locally developed solar cooker in Nigeria. So in Nigeria, there is need for the government and private investors to utilize the solar potentials through research and integrate its application into our current energy system. This is necessary as developing solar energy is an appropriate policy for reducing the dependence on imported energy and promoting environmental protection in the metropolis [7,41].

The parabolic solar cooker designed and fabricated in this study used a parabolic-shaped reflector to direct sunlight to a small area (absorber box) in order to generate heat for cooking.

\section{Materials and methods}

The Parabolic solar box consists of the following components: Parabolic dish, parabolic dish stand, box frame, insulation and double wall glass cover. The design was done according to Refs. [2,18]. The cooking vessel (or pot) was placed in a box positioned at the focal point, thus creating a heating condition similar to the conventional open fire cooking. The fabricated cooker was test ran at Landmark University, Omu-Aran, Kwara State, North Central Nigeria in December 2016. Subsequent tests were carried out in March, July, November 2017 and January 2018.

\subsection{Design calculation}

The solar box and parabolic cookers consist of the following components [19]; Parabolic reflector for the parabola; plane reflector for the box cooker; the wooden box which consists of glass cover, absorber and insulator.

\subsubsection{Concentrator reflector material}

Ashby material method was used in selecting the materials for the parabolic and box cooker.

\subsubsection{The shape of the reflector concentrators and the receivers}

The design of the shape of the reflector was done according to Lovegrove et al. [20].

\subsubsection{Parabolic dish concentrator size}

The size of the parabolic dish depends on the solar irradiances required by the solar cooker. Palavras et al. [21] method was used in the work.

\subsubsection{Aperture area size}

The total surface area of the solar concentrator upon which solar energy is incident is known as the aperture area of the dish [22], while Ghani [23] defined aperture area as the area that receives the solar radiation. The sizes of the solar concentrator enhance the cooker's thermal performance.

Therefore, the aperture area was calculated using eqn. (3.1) as stated by Lovegrove et al. [20] and El-Quedermi et al., [24].

$A_{a p}=\frac{\pi D_{a p}^{2}}{4}$

$A_{a p}=\frac{8 \pi}{3} f^{2}\left[\left(1+\left(D_{a p} / 4 f\right)^{2}\right)^{3 / 2}-1\right]$

$=\frac{22 \times 0.86^{2}}{7 \times 4}=0.581 \mathrm{~m}^{2}$

\subsubsection{Solar radiation reflected}

The solar radiation reflected from the concentrator was calculated using ASHRE [25] empirical model.

$I_{T}=I_{b}+I_{d}+I_{r}$

The total solar irradiance $I_{T}$ is what remains of extraterrestrial solar radiation after it had suffered atmospheric extinction. The empirical forms given by ASHRAE for the components of $I_{T}$ under clear sky are

$I_{b}=A e^{-\left(\frac{B}{\sin \alpha}\right)} \cos \theta_{g}$

$I_{d}=A C e^{-\left(\frac{B}{\sin \alpha}\right)} \cos \theta_{g}$

$I_{r}=\left(\rho_{r} \cos \theta_{r g}\right) A e^{-\left(\frac{B}{\sin \alpha}\right)} \cos \theta_{r}$

Where: $A, B$ and $C$ are constants determined for average days of the months.

\subsubsection{Focal length of the parabolic dish}

Thakkar et al. [22] defined the focal length (f) as the distance from the vertex to the focus. The focal length of the focal point from the dish concentrator was calculated using Lovegrove et al. [20] equation.

$\frac{f}{D_{a p}}=\frac{1}{4 \tan \left(\varphi_{\text {rim }} / 2\right)}$

$f=\frac{D_{a p}^{2}}{16 h}$

Where.

$f=$ focal length

$D_{a p}=$ Aperture diameter

$h=$ depth of the dish (height of the parabola measured from the base) 
$=\frac{860^{2}}{16 \times 110}=420.23 \mathrm{~mm}=42.023 \mathrm{~cm}$

\subsubsection{Size of the aperture receiver area}

The sizing of the aperture area of the receiver was calculated according to El-Quedermi et al., [24].

$A_{s}=\frac{8 \pi}{3} f^{2}\left[\left(1+\left(D_{a p / 4 f}\right)^{2}\right)^{3 / 2}-1\right]$
$A_{s}=\frac{8 \times 22}{3 \times 7} x(0.381)^{2}\left[\left(1+(0.8 / 4 \times 0.381)^{2}\right)^{3 / 2}-1\right]=1.039 m^{2}$

$A_{\text {rec }}=B+\frac{1}{2} p . l=0.0471+1 / 2(0.016) x 0.16 A_{\text {rec }}=0.0484 m^{2}$

\subsubsection{Geometric concentration ratio}

It is important to build solar dish with a concentration ratio greater than $10[23,26]$. Eqn. (3.5) was used to determine the concentration ratio of the dish as stated by Lovegrove et al. [20].

$C=\frac{A_{a p}}{A_{a b s}}$

$C=\frac{0.581}{0.0484}=12.0$

\subsubsection{Determination of rim angle}

The relationship between focal length with the rim angle and aperture diameter of the parabolic dish as given by Stine et al. [27], is: $\varphi_{\text {rim }}=\tan ^{-1}\left[\frac{8 f / D_{a p}}{16\left(f / D_{a p}\right)^{2}-1}\right]$

Where $\varphi_{\text {rim }}=$ Rim angle

$\varphi_{\text {rim }}=\tan ^{-1}\left[\frac{8 x 0.42 / 0.86}{16(0.42 / 0.86)^{2}-1}\right]$

$\varphi_{\text {rim }}=\tan ^{-1} 1.387=.54 .2^{\circ}$

The views as well as the dimensions of the parabolic cooker are as shown in Figs. 1-4.

\subsection{Material selection}

The material selection was based on Ashby's book and it did shed light that material is inherently based on at least 5 interrelated criteria:

- Function of structural component

- Materials available and their properties

- Shape and size of structural component

- Process used to manufacture structural component

- Cost and Availability (of both material and process)

Since the aim of the work is to design and fabricate the component, it is imperative that we know the function of all aspects and the likely materials that can suit the purpose of the functional area. We took these functions individually, determined the likely characteristics, chose the materials, and their alternates that can serve the function, analysed them and took decision based on qualities, cost and availability of the material.

\subsubsection{Parabolic dish}

The two materials that had the potentiality to be used as the parabolic dish was stainless steel and aluminium. From the physical properties, stainless steel weighs more with a density of $7.64 \mathrm{~g} / \mathrm{cc}$ compared to $3.97 \mathrm{~g} / \mathrm{cc}$ of that of the Aluminium. This makes stainless steel heavier during material handling. Thermally it takes
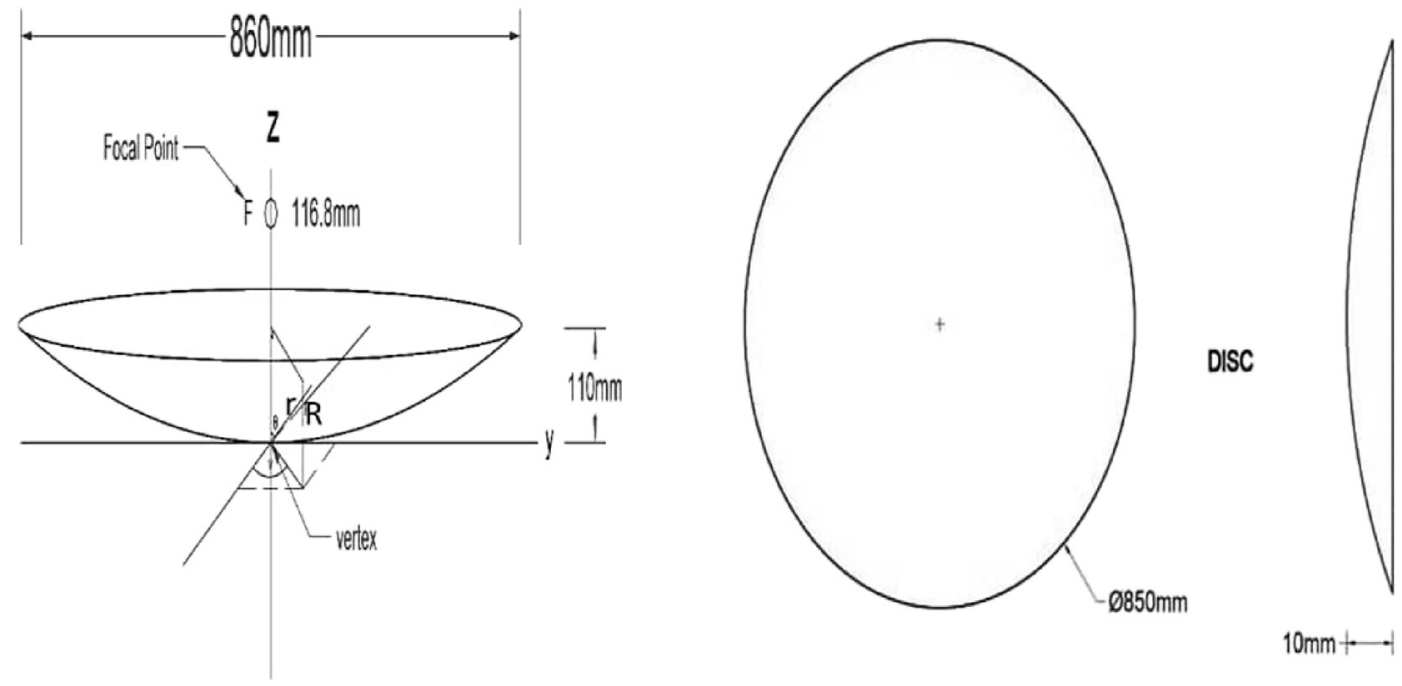

Fig. 1. Plane and sectional drawing of the parabolic dish. 

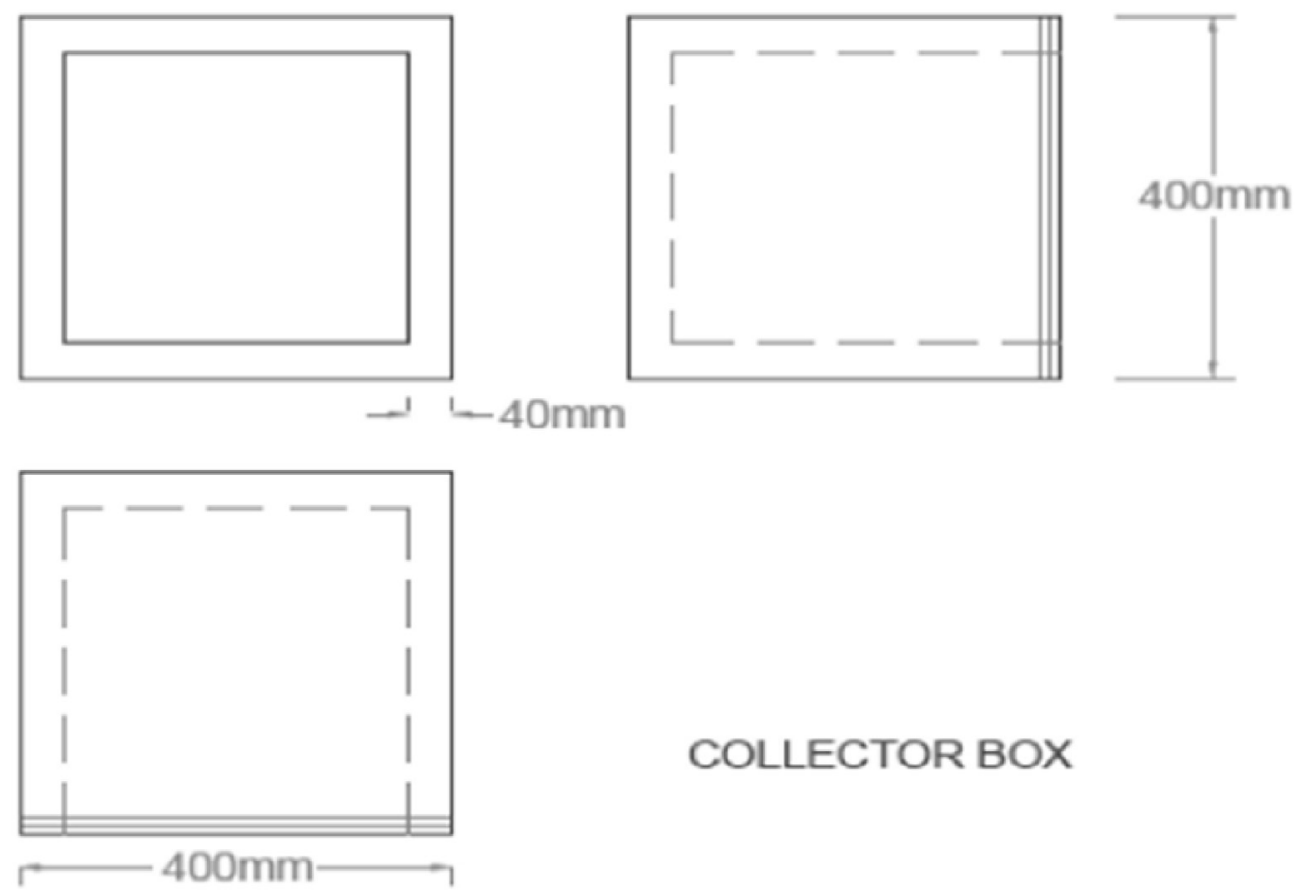

Fig. 2. Plane and Sectional Drawing of the Collector box.

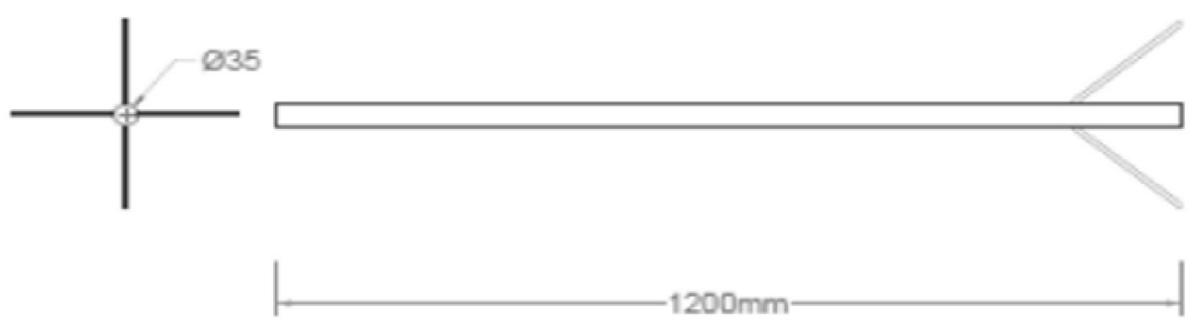

COLLECTOR STAND
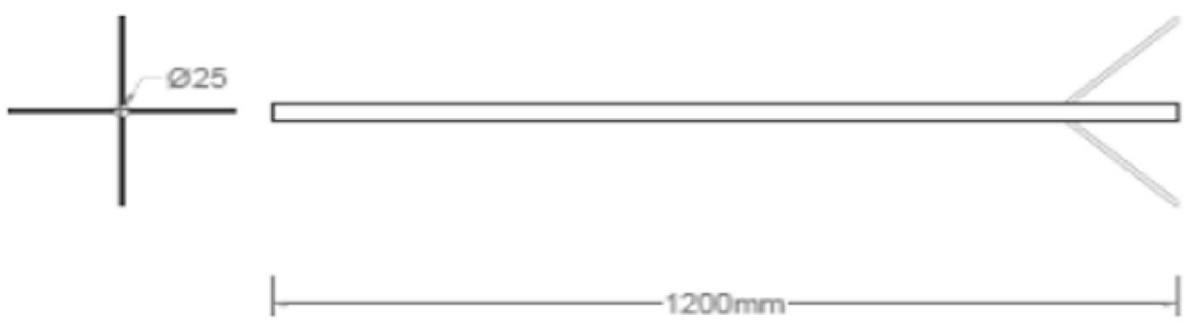

DISC STAND

Fig. 3. Plane and sectional drawing of the dish stand.

about $100^{\circ} \mathrm{C}$ before expansion can occur compared to $20^{\circ} \mathrm{C}$ for aluminium. Since the operation does not require very high temperature at the parabolic dish. Aluminium stood a better option. Both materials have a considerable polished face and can perform the same action of reflecting the sun's ray.

Aluminium has a "whiter colour," and loses its lustre faster than stainless. It also dissipates heat much faster because of its higher conductivity. The two forms of heat transfer involved are Conduction and Radiation. The ability to radiate heat is measured in emissivity. The emissivity of non-published aluminium is around
0.09 while stainless steel 304 is 0.6 , which means the lower the value, the more the heat reflected. The conductivity of aluminium is about $145 \mathrm{~W} / \mathrm{m}$ C Stainless steel is $16.26 \mathrm{~W} / \mathrm{m}-\mathrm{C}$ [28].

\subsubsection{Parabolic dish stand}

Materials from the African mahogany wood and mild steel were considered for this project. The modulus of elasticity and the density of mild steel is far greater than that of the African mahogany wood. We considered the cost per stiffness ratio, still employing the Ashby graph, then we saw that the cost of wood was 


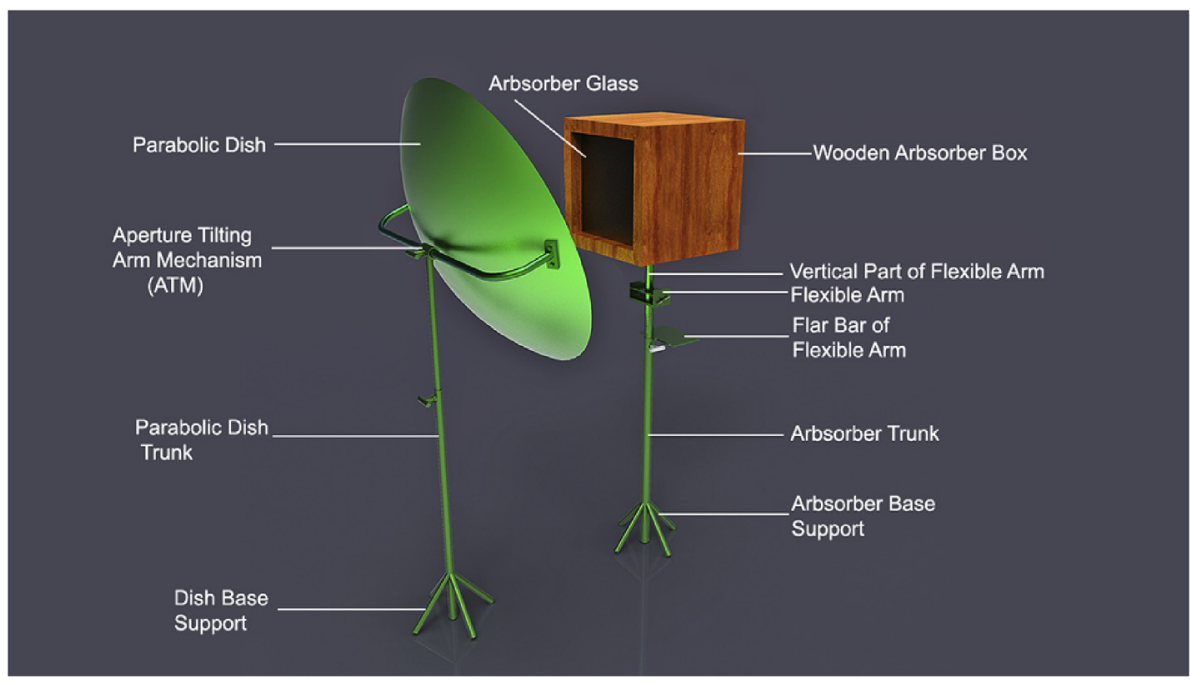

Fig. 4. Designed parabolic cooker in 3D.

cheaper than mild steel. But considering other factors like corrosion resistance, availability and workability, mild steel stood out as a better material [29].

\subsubsection{Box frame}

Most frameworks are done with concrete and plywood when the thermal conductivity is required to be very small. Looking at the rapture of a material, which is defined as the stress in a material just before it yields in a flexure test. The concrete has a better and higher value of $0.00470-0.00600 \mathrm{GPa}$ compared with that of plywood of $0.0483-0.0689 \mathrm{GPa}$. This is about 10 times the value of plywood. Concrete has a higher thermal conductivity than that of plywood, having a value of $0.750 \mathrm{~W} / \mathrm{m}-\mathrm{K}$ compared with $0.110-0.147 \mathrm{~W} / \mathrm{m}-\mathrm{K}$ of plywood. Since the basic characteristics, we looked at was thermal conductivity. The plywood had more advantage than concrete. Additionally, concrete is bulky and would cause poor ergonomics during installation and usage due to its low flexibility [29].

\subsubsection{Insulation}

The prospective materials are sawdust/wood chipping sand rock wool. As stated earlier, the major characteristic is the thermal conductivity of the materials in question. Rock wool has a smaller thermal conductivity of $0.0400 \mathrm{~W} / \mathrm{m}-\mathrm{K}$ compared to the thermal conductivity of sawdust which is stipulated at $0.110-0.147 \mathrm{~W} / \mathrm{m}-\mathrm{K}$. Another advantage of rock wool is its weight. Rock wool weighs far less than sawdust. This invariably means that the overall weight of the box cooker, when integrated with sawdust as the insulating material, will be higher than when rock wool was used. However, sawdust was chosen as the insulator material because rock wool was not readily accessible at the time being considered.

\subsubsection{Glass cover}

The material to use here is glass. This is because from literature. Glass has been the most consistent material used in the past for solar applications and transmittance of energy. The surface of a glass is often smooth since during glass formation the molecules of the super-cooled liquid are not forced to dispose in rigid crystal geometries and can follow surface tension, which imposes a microscopically smooth surface. These properties, gave glass its clearness, and can be retained even if glass is partially lightabsorbing-i.e., coloured. Glass has the ability to refract, reflect, and transmit light following geometrical optics, without scattering it. It is used in the manufacture of lenses and windows. Common glass has a refraction index around 1.5. This may be modified by adding low-density materials such as boron, which lowers the index of refraction (see crown glass), or increased (to as much as 1.8) with high-density materials such as (classically) lead oxide (see flint glass and lead glass), or in modern uses, less toxic oxides of zirconium, titanium, or barium. These high-index glasses inaccurately known as "crystal" when used in glass vessels causes more chromatic dispersion of light, and are prized for their diamond-like optical properties.

According to Fresnel equations, the reflectivity of a sheet of glass is about $4 \%$ per surface (at normal incidence in air), and the transmissivity of one element (two surfaces) is about $90 \%$. When considering the thermal strain, the Ashby chart for assessing thermal distortion can be employed. The contours show the value of the ratio $\lambda / \alpha(\mathrm{W} / \mathrm{m})$. Materials with a large value of this design index show small thermal distortion. They define the guideline. With glass having its $\mathrm{C}$ value close to $10^{7}$, thermal distortion will is minimal [28].

\subsection{Construction of the cooker}

The solar parabolic dish collector is made from a $0.5 \mathrm{~mm}$ thick Aluminium sheet to reduce heat loss. A manual sun tracking mechanism made of iron bars was also incorporated to constantly adjust the cooker to the sun's direction. Thin linings of Aluminium foil paper were used as the reflector on the outer surfaces of the dish [30]. The bottom of the box is made of China plane wood of thickness $1 / 4$ in $(0.635 \mathrm{~cm})$. The inner surfaces of the box were lined with Aluminium foil. The solar absorber is made from $0.54 \mathrm{~mm}$ thick smooth Aluminium sheet. The Aluminium sheet in the box is painted matte black to form the absorber. The cooking pots are also painted matte black. The box is constructed in the form of inverted square pyramidal frustum. It is obvious from the figure that the length of the slanting sides of the absorber is $\sqrt{15^{2}+7.5^{2}}=16.77 \mathrm{~cm}$. The inner base of the wooden box is covered with helical/spiral shaped wooden chips. The chips are waste products of chiseling process and sawdust is then poured on the chips to serve as insulation layer of $5 \mathrm{~cm}$. The contact surface between the cover and the box are lined with rubber materials. 


\subsection{Principles of operation}

The parabolic solar cooker uses sun energy as the heat source for cooking different kinds of food. Three basic phenomena are employed in the design and operation of the cooker. These are:

$>$ The parabolic dish receives rays of light from the sun and concentrates it into a double walled absorber box at the focus point.

$\triangleright$ The box cooker acts as an absorber and converts the solar radiation received to heat for cooking [31].

\subsection{Experimental set-up and procedure}

Tests were started at around 10:00 a.m. and were stopped at around 5:00 p.m.

$\checkmark$ The cooker was kept under shading before the start of the tests and brought to receive solar radiation.

$\checkmark$ Tracking of the cooker was done manually every $10 \mathrm{~min}$.

$\checkmark$ Thermocouples were attached to the centre of the bottom absorber plate during the No-load (stagnation) test and were immersed in water during the boiling test.

$\checkmark$ In the test, $2 \mathrm{~L}$ of water divided equally between two identical pots was used at each start of the Load test (Sensible test).

$\checkmark$ Campbell Scientific LTD Anatomy of a weather station installed in Landmark University Omu-Aran, Kwara State was used to measure the solar radiation, wind speed, direction of the sun and wind direction.

$\checkmark 4$ Channel digital data logging thermometer connected to KType thermocouple was used to record the ambient temperature.

$\checkmark$ Results were recorded every $10 \mathrm{~min}$.

\subsection{Energy and exergy analysis}

\subsubsection{Energy analysis}

Energy input is given by Ref. [32].

$E_{i}=I_{a v} x A_{a p}$

Where $E_{i}$ is energy input, $I_{s} i$ s the average solar radiation and $A_{a p}$ is area of aperture of solar cookers.
Also the energy output may be calculated as follows [32].

$E_{o}=M_{w} C_{w} \frac{\left(T_{f}-T_{i}\right)}{d t}$

Where is $E_{o}$ is energy output, $M_{w}$ mass of water, $C_{w}$ is specific heat of water, $T_{f}$ is final temperature of water, $T_{i}$ is initial temperature of water, $\mathrm{d} t$ is time difference.

Therefore, the ratio of energy output to input is given by

$\eta=\frac{E_{o}}{E_{i}}=\frac{\text { Energy output }}{\text { Energy Input }}$

\subsubsection{Exergy analysis}

The exergy input of the parabolic cooker can be calculated using eqn. (3.15) [32].

$E x_{i}=I_{S}\left[1+\frac{1}{3}\left(\frac{T_{a b}}{T_{S}}\right)^{4}-\frac{4}{3}\left(\frac{T_{a b}}{T_{S}}\right)\right] A_{a p}$

$T_{a}$ is the ambient temperature (K). The sun's black body temperature of 5762 .

$\mathrm{K}$ results in a solar spectrum concentrated primarily in the 0.3-3.0 $\mu \mathrm{m}$ wavelength Band [33]. Although the surface temperature of the sun $\left(T_{s}\right)$ can be varied on the earth' surface due to the spectral distribution, the value of $5800 \mathrm{~K}$ has been considered for $T_{S}$.

While the exergy output can be calculated using eqn. (3.16) [12], Kreith \& Kreider [33]; Pandey et al. [17].

$E x_{o}=\frac{M_{w} \cdot C_{w}\left[\left(T_{f}-T_{i}\right)-T_{a} I n \frac{T_{f}}{T_{i}}\right]}{d t}$

The exergy efficiency is obtained using eqn. (3.17) [34,42].

$\phi=\frac{E x_{0}}{E x_{i}}=\frac{M_{w} \cdot C_{w}\left[\left(T_{f}-T_{i}\right)-T_{a} I \frac{T_{f}}{T_{i}}\right]}{d t}=\frac{\text { Exergyoutput }}{I_{S}\left[1+\frac{1}{3}\left(\frac{T_{a b}}{T_{s}}\right)^{4}-\frac{4}{3}\left(\frac{T_{a b}}{T_{s}}\right)\right] A_{a p}}$

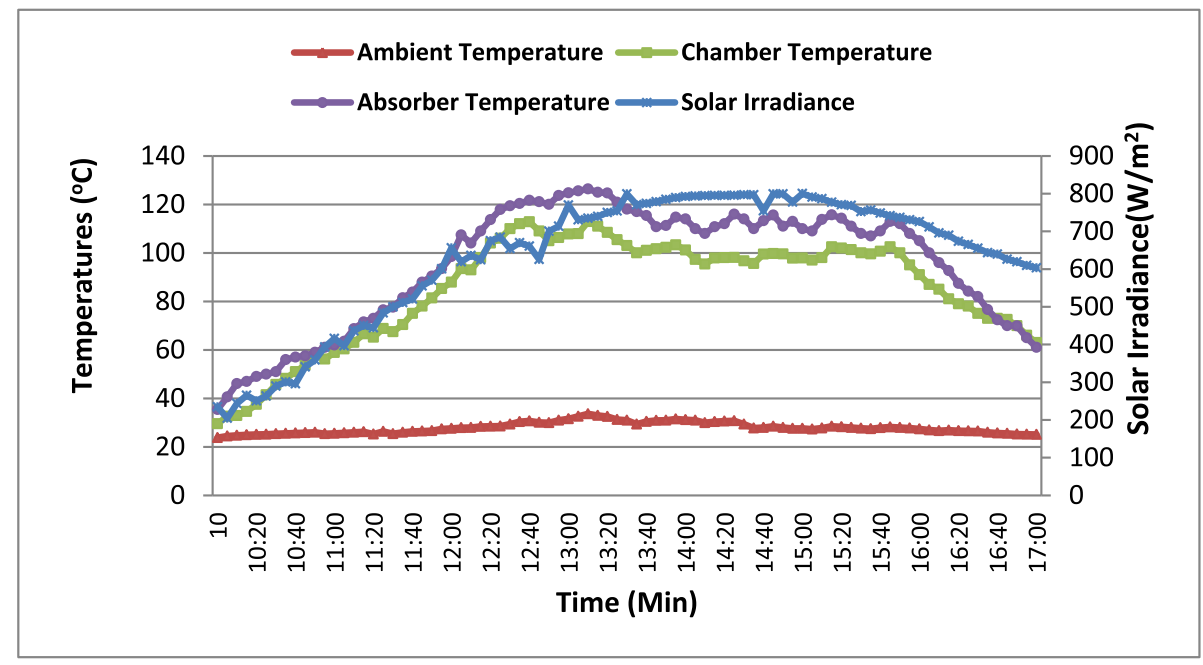

Fig. 5. Temperatures vs. Time during Stagnation Test on 6th February 2017. 


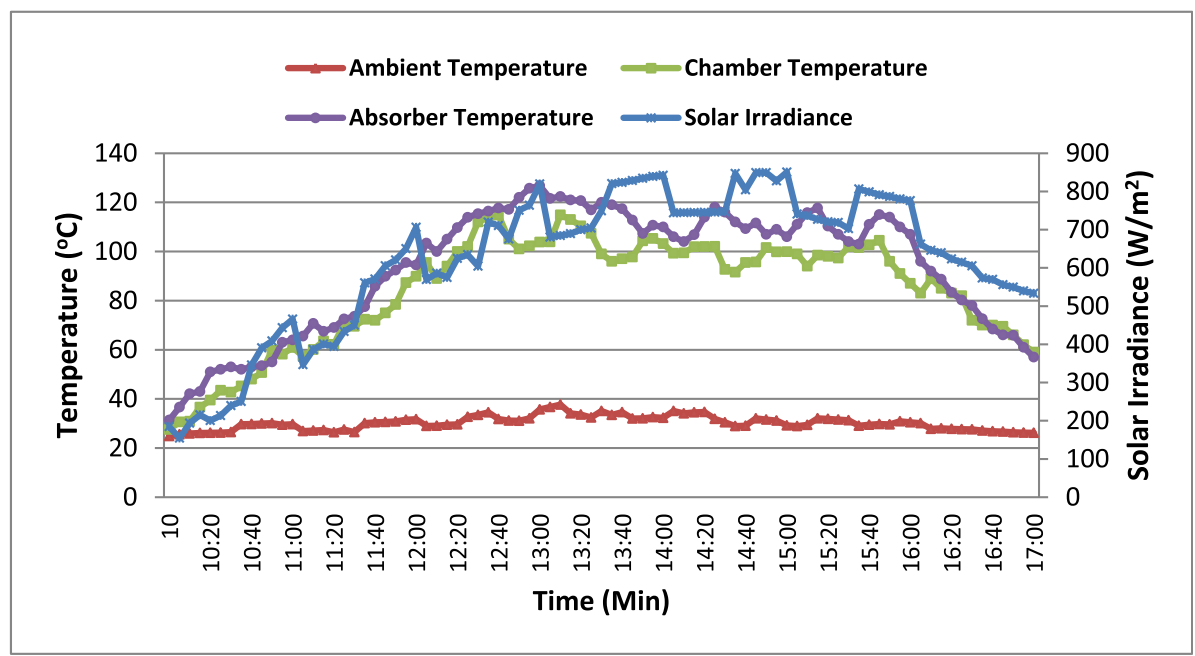

Fig. 6. Temperatures vs. Time during Stagnation Test on 22nd April 2017.

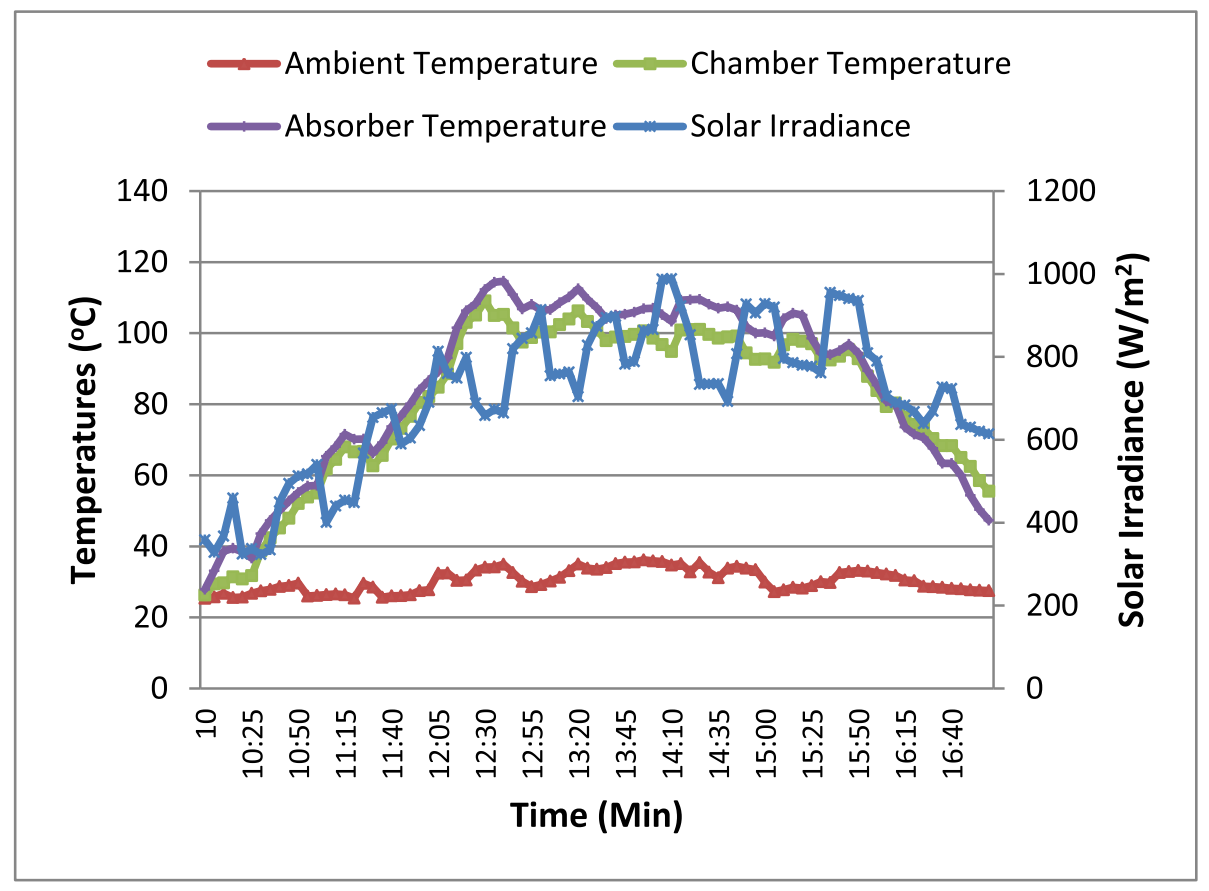

Fig. 7. Temperatures vs. Time during Stagnation Test on 19th June 2017.

\section{Results and discussion}

Figs. 5-10 shows variations in the ambient, chamber, absorber and water temperature during stagnation (no-load test) and sensible heat (load tests) carried out in Landmark University, Omuaran, Kwara State. The change in the temperature was due to variations in solar radiation. The least temperature recorded for stagnation test was $118.2^{\circ} \mathrm{C}$. This temperature is higher than $100^{\circ} \mathrm{C}$, thus, the cooker can be recommended for drying crops, cooking and heating purpose. Food can be cooked below $111^{\circ} \mathrm{C}$ such as Grains $\left(100-110^{\circ} \mathrm{C}\right)$, seafood $\left(63^{\circ} \mathrm{C}\right)$, Beef, Pork, Veal, Turkey and Chicken $\left(71^{\circ} \mathrm{C}\right)$, Eggs $\left(71^{\circ} \mathrm{C}\right)$ [35], while Crops are dried at a temperature below $100^{\circ} \mathrm{C}[36]$. It was observed that the temperatures of the cookers increased gradually as the time increased until it got to a peak level of around 12:30-1: 30 p.m. local time. Also, the time taken to boil the water was $105 \mathrm{~min}$. The delay in boiling time is as a result of poor weather and instability in solar radiation. It was also observed that the time taken to boil the water was faster in the Month of March compared to the month of January, July, October and December. The gradual reduction in sensible temperatures can be attributed to deterioration (Scratches of the foil, dirt, weakness of the joints) of the cookers with time $[37,40]$.

The Energy and Exergy Efficiencies plotted based on $8 \mathrm{~h}$ sensible tests carried out on March 2017. Further reading was taken in July, October and December 2017. And lastly January 2018 are shown in Figs. 11-13. The energy and exergy efficiencies of parabolic cooker decrease gradually as the temperature difference/time increased until there was little or no energy and exergy in the cooker around 5:00 p.m. local time. The peak energy efficiency for the Month of March, July and October are 43.2\%, 33.7\% and 40.1\% respectively, while the exergy efficiencies are $39.7 \%, 30.7 \%$ and $36.4 \%$ respectively. The maximum energy and exergy efficiencies occurred 


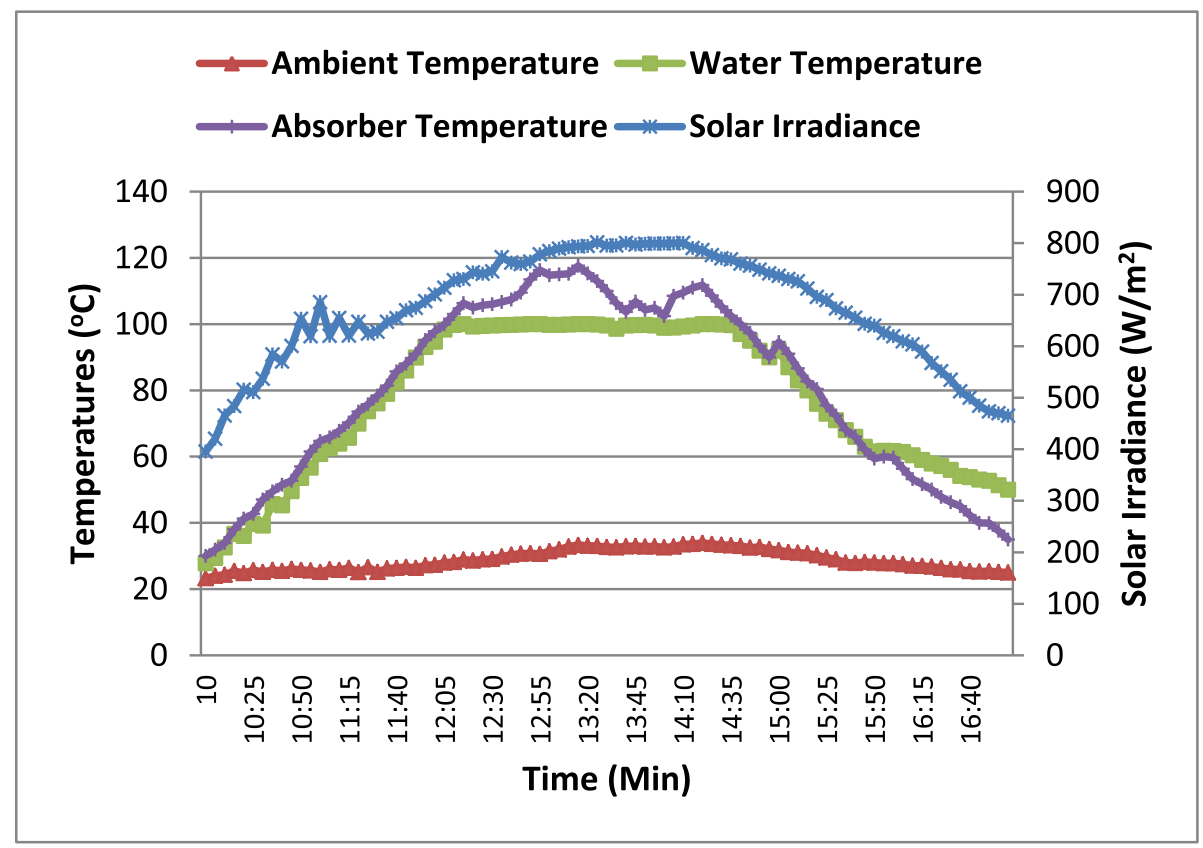

Fig. 8. Temperatures vs. Time during Sensible Test on 15th December 2016.

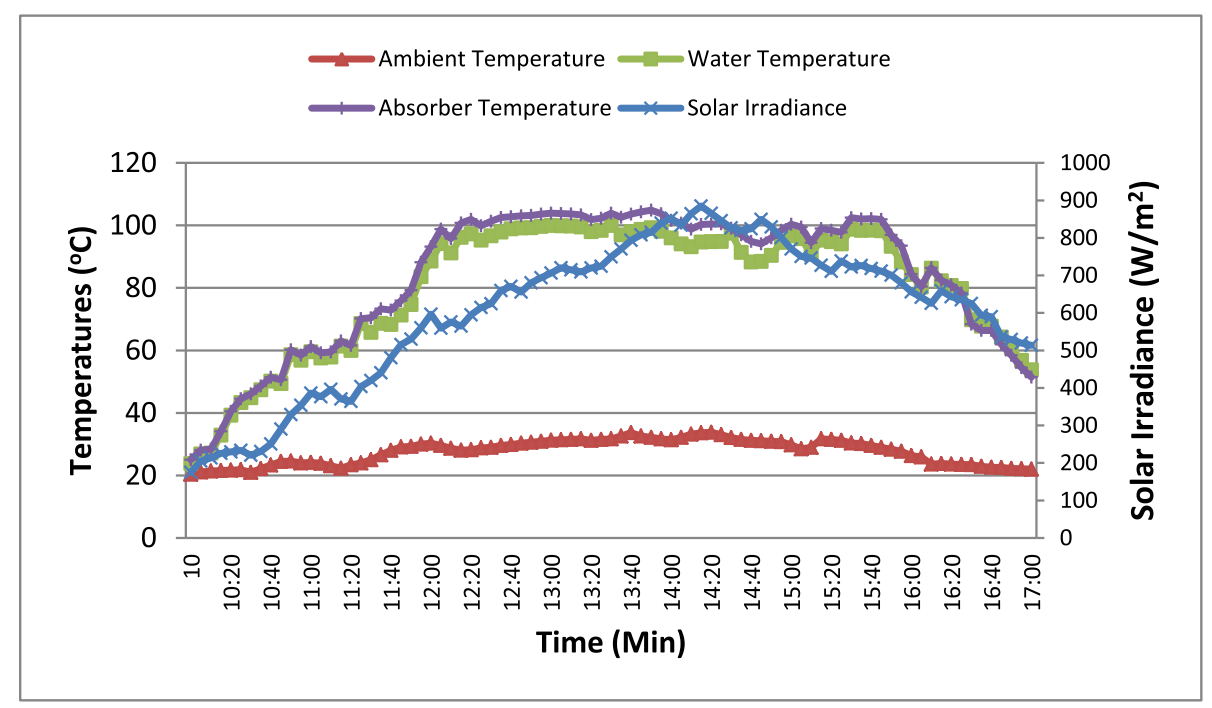

Fig. 9. Temperatures vs. Time during Sensible Test on 4th January 2018.

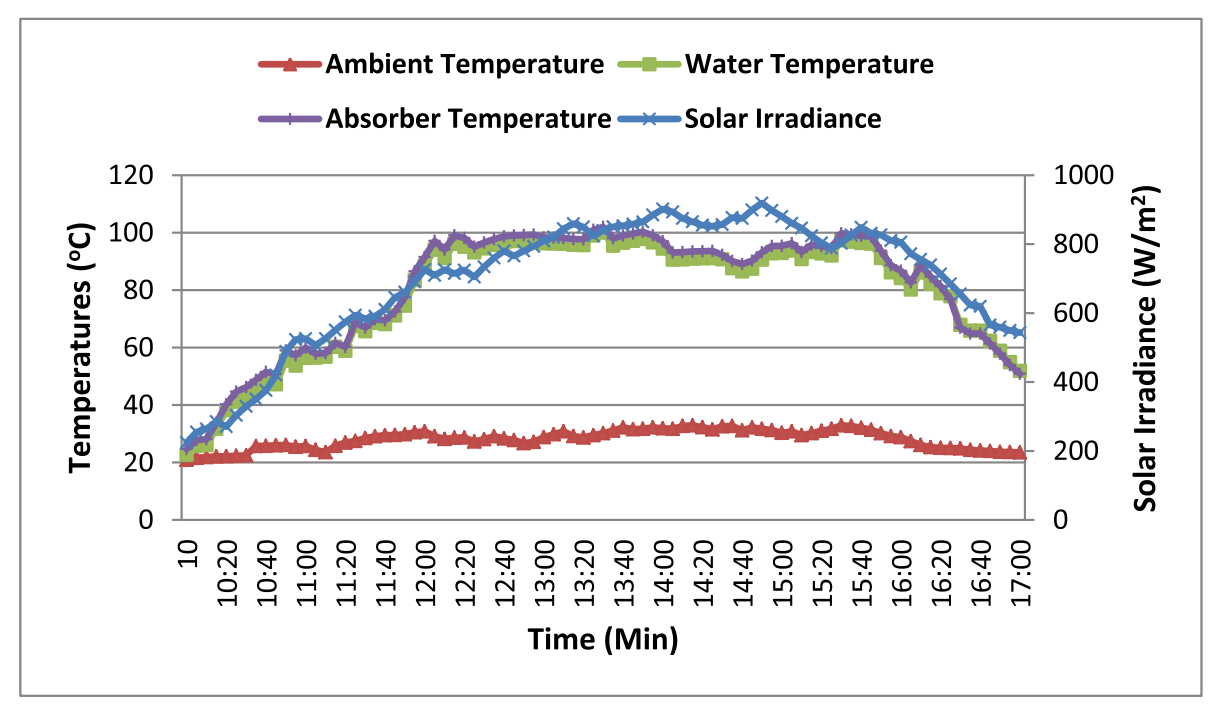

Fig. 10. Temperatures vs. Time during Sensible on 6th January 2018. 


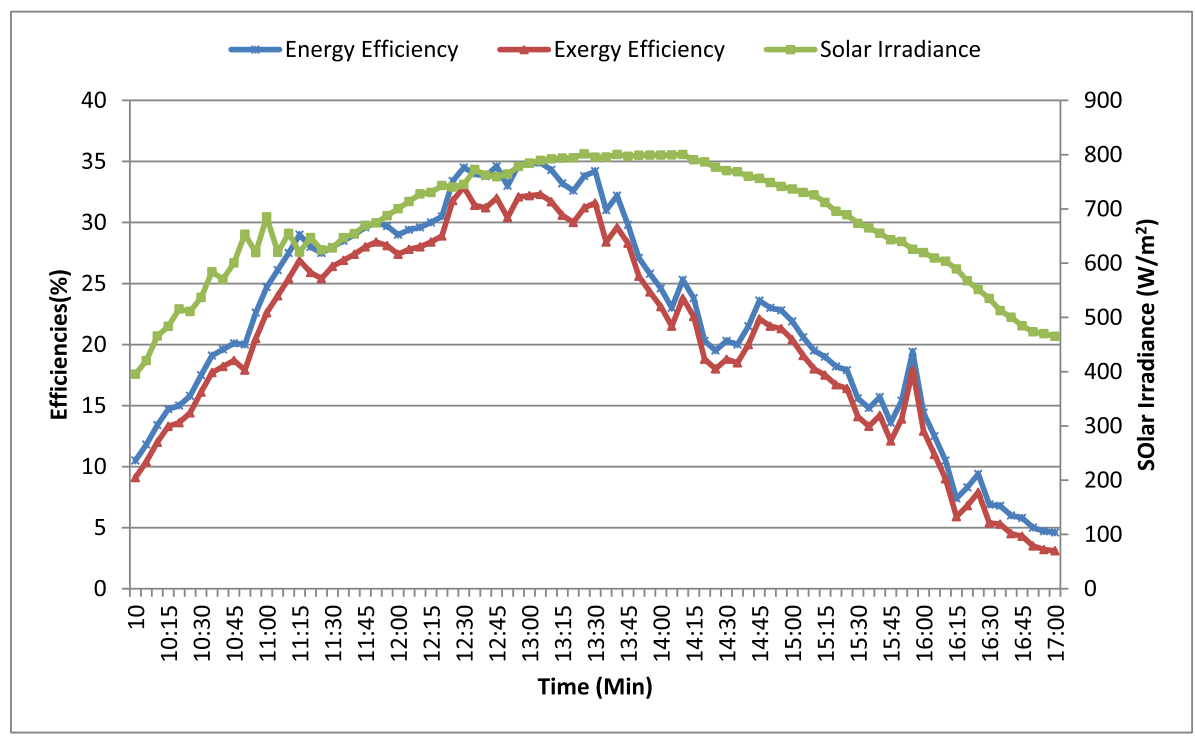

Fig. 11. Energy and Exergy Efficiency against time of Parabolic Solar Cooker 8th March 2017.

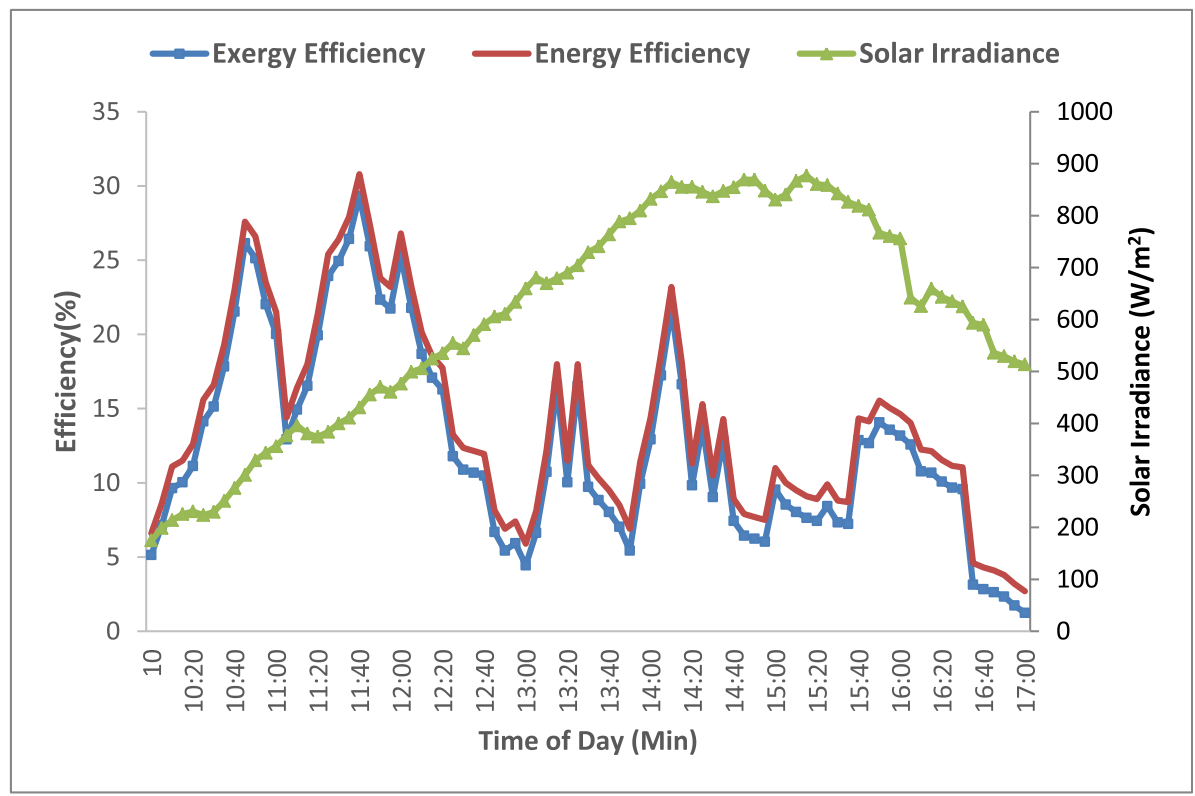

Fig. 12. Energy and Exergy Efficiency against time of Parabolic Dish Cooker 20th July 2017.

around 12:30-1:30 p.m. local time. The energy and exergy efficiencies were higher in the month of March compared to the Month of July, and October due to the increase in solar irradiance and clearness of the sky during the period of the test. The decrease in efficiencies of the cookers is due to deterioration of the aluminium foil used as the reflector causing poor reflector of rays (radiation) into the absorber box and myth of overcast sky, while the fluctuation in efficiencies was as a result of fluctuating nature of solar radiation [16]. The decrease in energy efficiency of the cookers was attributed to the optical and thermal losses from the reflector and pot, while the reduction of exergy efficiency of the cooker is due to entropy increase of the cooker together with its surrounding and irreversibility in the cooker caused by empty space minimization and thermal inertial effect [22].

It was deduced that the exergy efficiency is lower compared to the energy efficiency mainly due to large exergy of the escaping insolation and additionally due to the degradation of the insolation absorber on the surface of the reflector and the cooking pot as seen in Figs. 11-13. The sudden drop in energy and exergy efficiencies as shown in Figs. 12 and 18 was attributed to variations in atmospheric conditions such as total amount of water vapour in the air, turbidity and increase in significant levels of cloud cover. The decreases were also caused by changes in the position of the sun.

Fig. 14 shows the Pareto graph of energy efficiency of parabolic dish cooker which was used to determine which factor (main or interacted) should be truncated from the mathematical model. Any factor below the 1.964 ( $5 \%$ level of significance) margin line should be truncated from the Design of experiment (DOE). Hence, $A B C D$, $\mathrm{BCD}, \mathrm{BD}, \mathrm{ABD}, \mathrm{C}$ and $\mathrm{AC}$ should be truncated.

The main plot shows how individual factors affect the general efficiency of the system. Fig. 15 indicates that $\mathrm{I}_{\mathrm{s}}$ plays a very vital role as it shows an increase, which increases the general efficiency. 


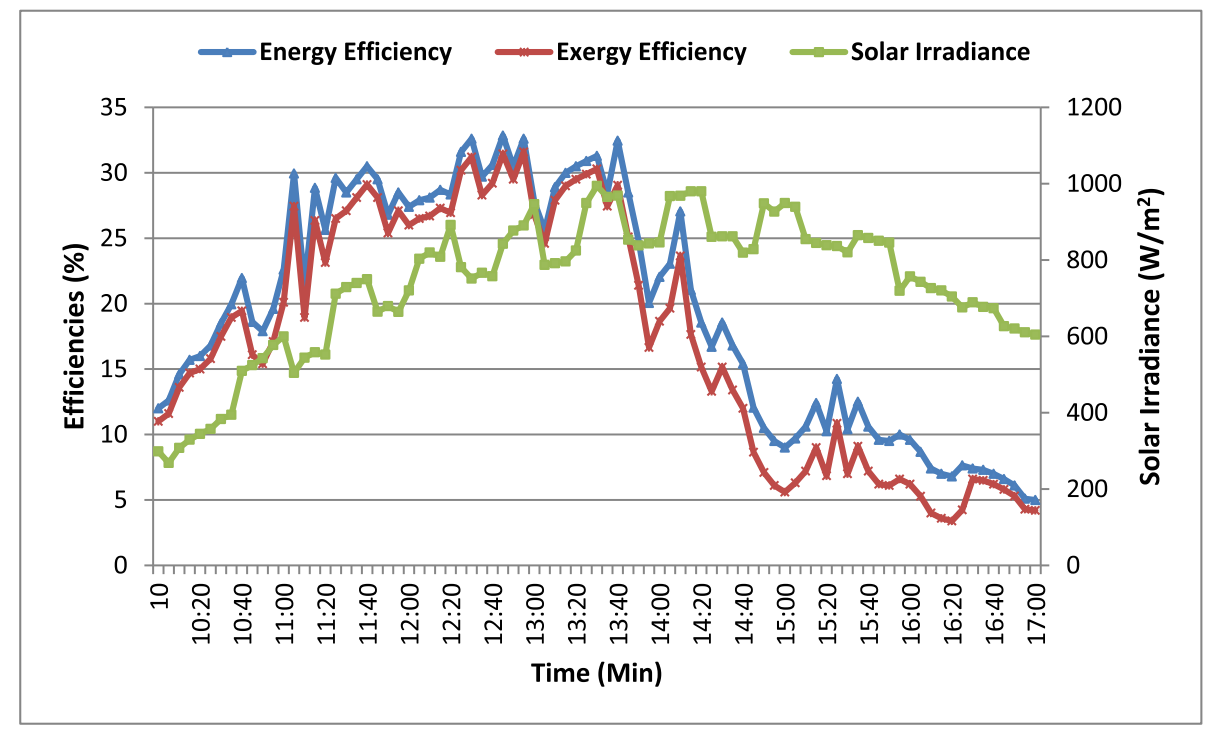

Fig. 13. Energy and exergy efficiency against time of parabolic dish cooker 5th October 2017.

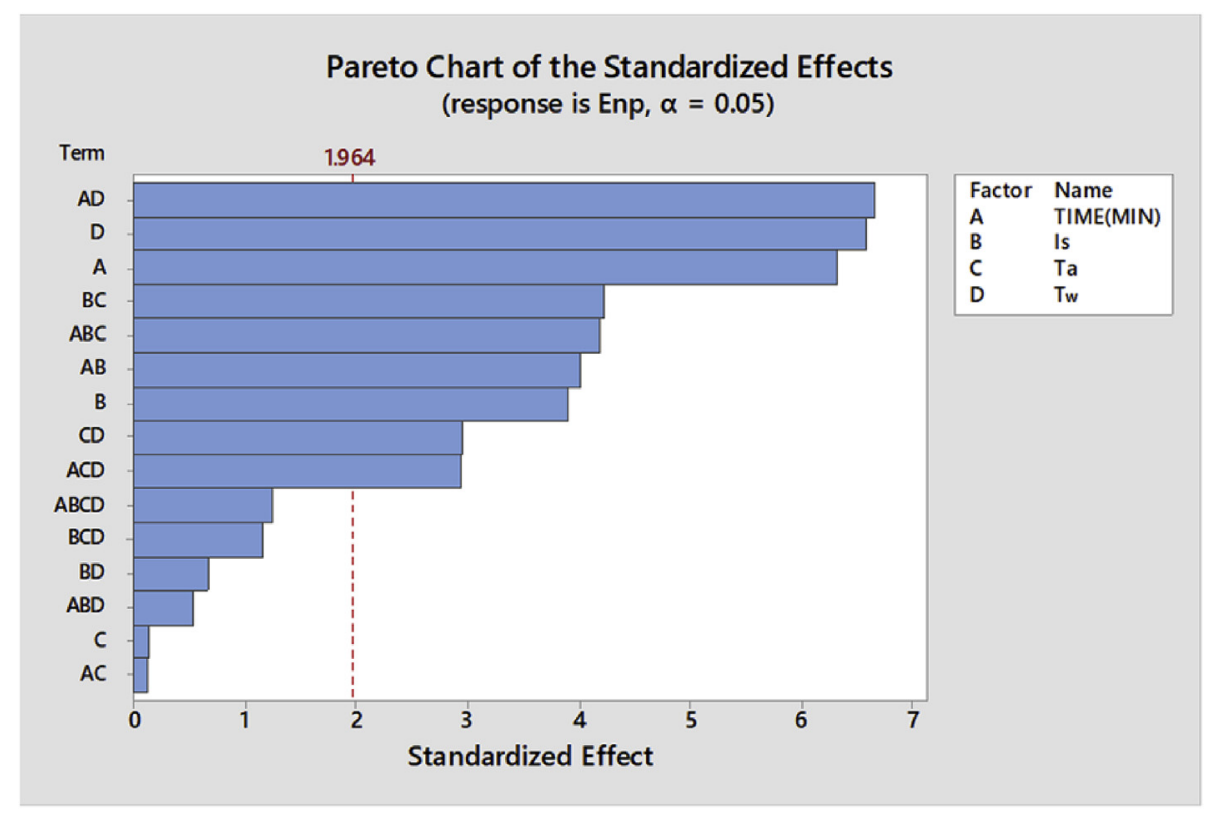

Fig. 14. Effects Pareto for Energy Efficiency of Parabolic cooker.

The reset factors gave its best if their values are reduced.

Just like the main plot, the interaction plot shows how the efficiency was affected when two factors were brought together to play a role as shown in Fig. 16. It can be deduced from the figure that two factors have a great effect on the energy efficiency of the box cooker. Solar irradiance \& Time, its interaction possessed the highest interactions factor for energy efficiency.

Fig. 17 shows the graphical representation of the interaction plot showing how two factors play their effect on the general efficiency of the system.

Figs. 18-20 shows the mathematical model of Energy and Exergy behaviour with time as a result of temperature difference. The predicted results were obtained from the mathematical expression derived from the design of experimental using Minitab software. The model equations can reproduce the experimental results, without necessarily performing an experiment. The energy and exergy results of the cookers gathered during sensible test were compared using descriptive and inferential statistical methods. One-way Analysis of Variance (ANOVA) was carried out at $5 \%$ significance level to evaluate significant differences between the parabolic and solar box cooker throughout the period of this test. Further statistical analysis using one factor or one-way analysis of variance shows that there was no significant difference observed between the experimental and predicted results obtained for exergy and energy efficiencies of both cookers as $p>0.05$. This means that the mathematical models were able to simulate and reproduce the experimental data, thereby making the model responsive. Also, the parabolic and box cookers possessed the same behaviour and the mathematical model used in describing the performance of the cooker is correct. 


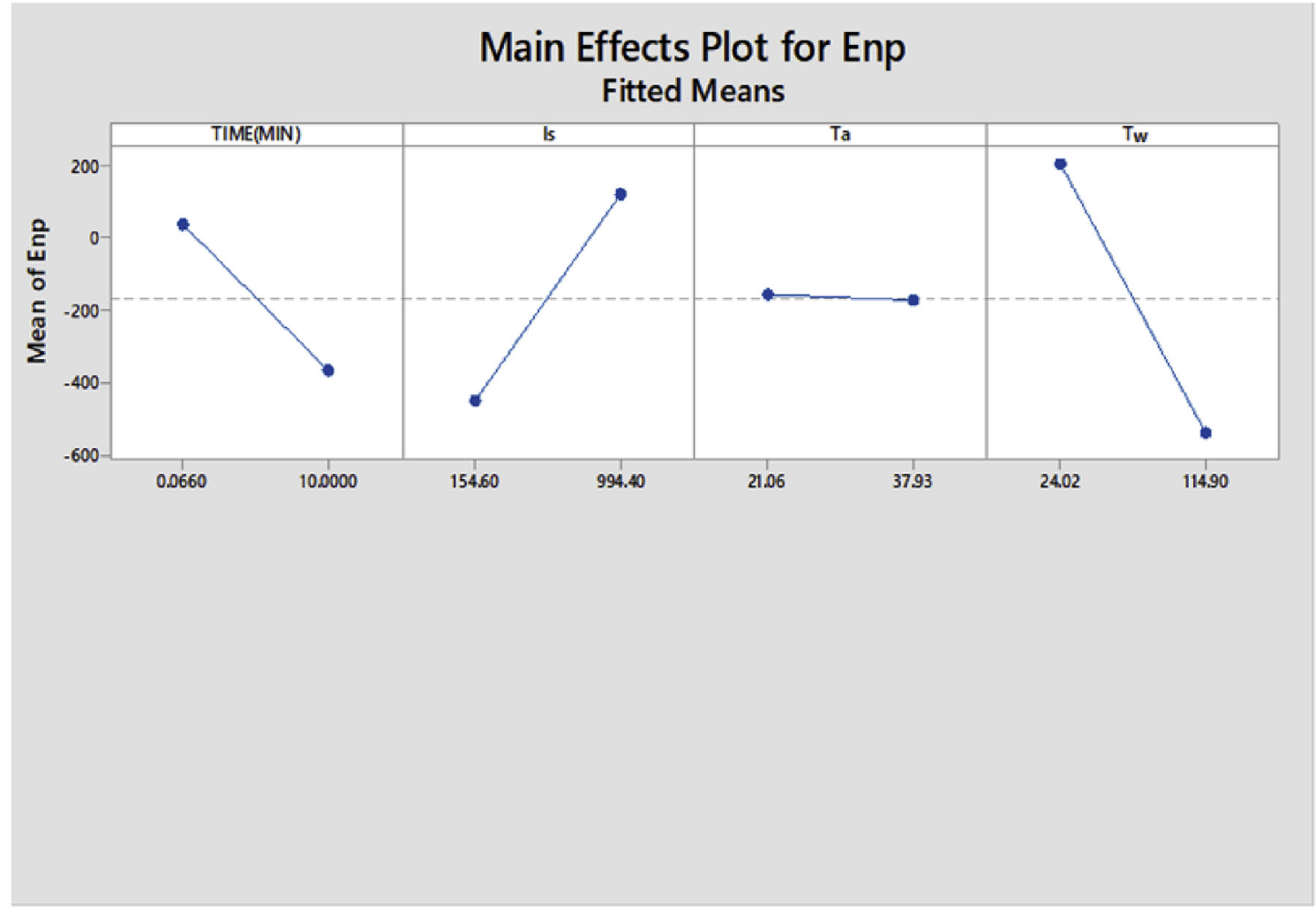

Fig. 15. Main effect plot for energy efficiency of parabolic dish cooker.

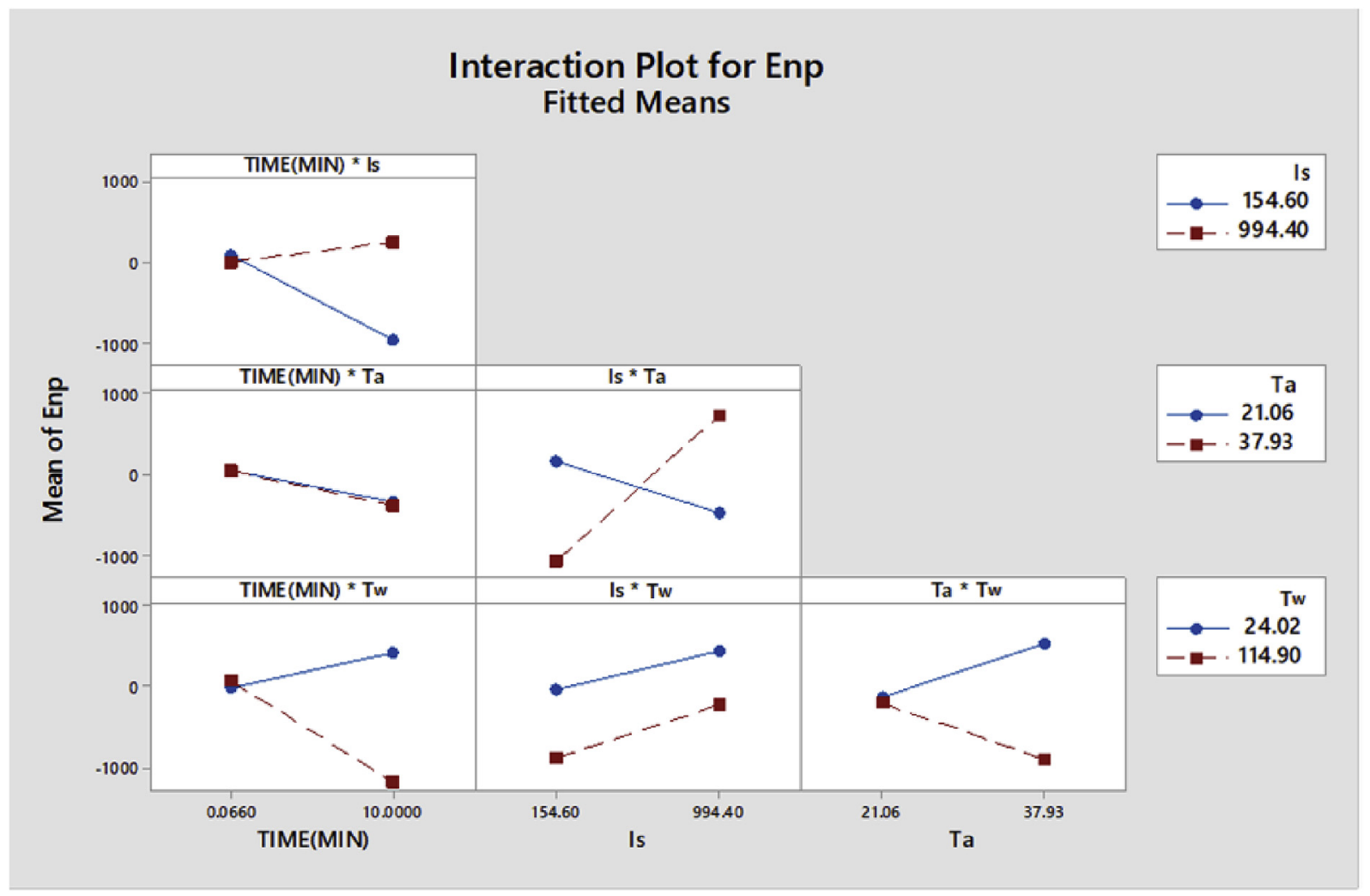

Fig. 16. Interaction plot for energy efficiency of parabolic dish cooker. 


\section{Contour Plots of Enp}
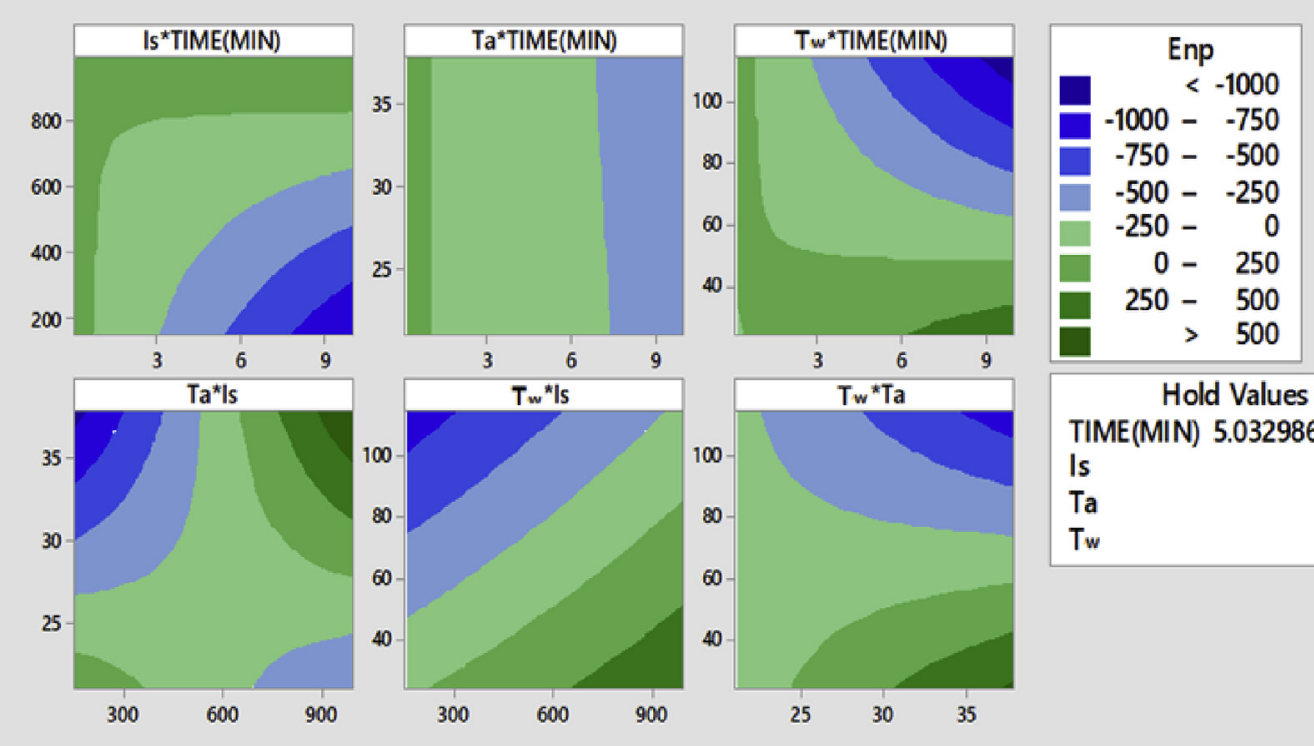

Hold Values TIME(MIN) 5.03298611111111 Is $\quad 574.5$

$\mathrm{Ta}$

29.495

$T_{w}$

69.46

Fig. 17. Contour plot for energy efficiency of parabolic dish cooker.

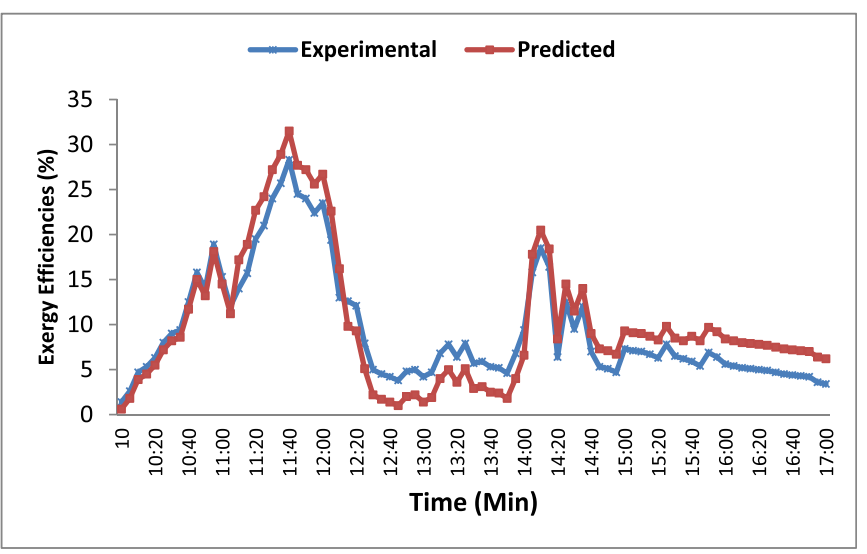

Fig. 18. Experimental and Predicted Energy Efficiency for parabolic dish cookers on 24th July 2017.

\section{Conclusion}

A solar cooker was fabricated to help reduce the problems associated with cooking fossil fuels (fuelwood, kerosene and gas) which border on environmental impact, health, cost and safety. This work anchored the need to solve these problems using locally built cheap technology that is powered by free available energy resource (solar) in Nigeria. The parabolic cooker was designed and constructed using local sources materials in Nigeria. Proper selection of materials was carried out to ensure optimum performance. An experimental investigation was carried out on the produced model in Omu-Aran Metropolis, Kwara State, Nigeria in December
2016. Thereafter other investigations were carried out from January to December 2017 and lastly in January 2018 between the hours of 10:00 a.m. to 5:00 p.m. local time for both stagnation and sensible heating, using $2 \mathrm{~L}$ of water at every experiment. During the no-load test, maximum stagnation temperature recorded was $121.7^{\circ} \mathrm{C}$, which is higher than $100^{\circ} \mathrm{C}$, thus, the cooker can be recommended for drying crops, cooking and heating purpose [38]. While the peak temperature obtained during load-test (sensible test) by the parabolic solar cooker was $100{ }^{\circ} \mathrm{C}$ between the hours of $12: 30$ noon and 1:30 p.m. local time which basically represents the ideal time to use the cooker. The cooker is recommended for pre-heating process as the water can retain higher temperature than the absorber during cooling process meaning that the interval of sterilization can be prolonged in the cooker. The variation in temperature is attributed to roughness in the foil, dirt, and increase in wind speed and myth of overcast skies. The delay in boiling time is as a result of poor weather and instability in solar radiation. The energy efficiency of parabolic and box cooker are 44.2 and $39.5 \%$ respectively, while their exergy efficiency is 41.3 and $38.3 \%$ respectively for sensible heating of $1 \mathrm{~L}$ of water. Also in case of $2 \mathrm{~L}$ of water is 35.6 and $30.1 \%$ respectively. The parabolic cooker is more efficient than the solar box cooker as it possessed greater exergy and energy efficiency. Also, it can be observed from the experimental results that the cookers can perform effectively in the month of March than the month of January, April, July, November and December due to the increase in solar irradiance and clearness of the sky during the period of March.

Design of Experiment was used to obtain mathematical expressions which were used to calculate the theoretical values of energy and exergy efficiencies using Minitab and excel solvers. Statistical analysis using one-way analysis of variance shows that 


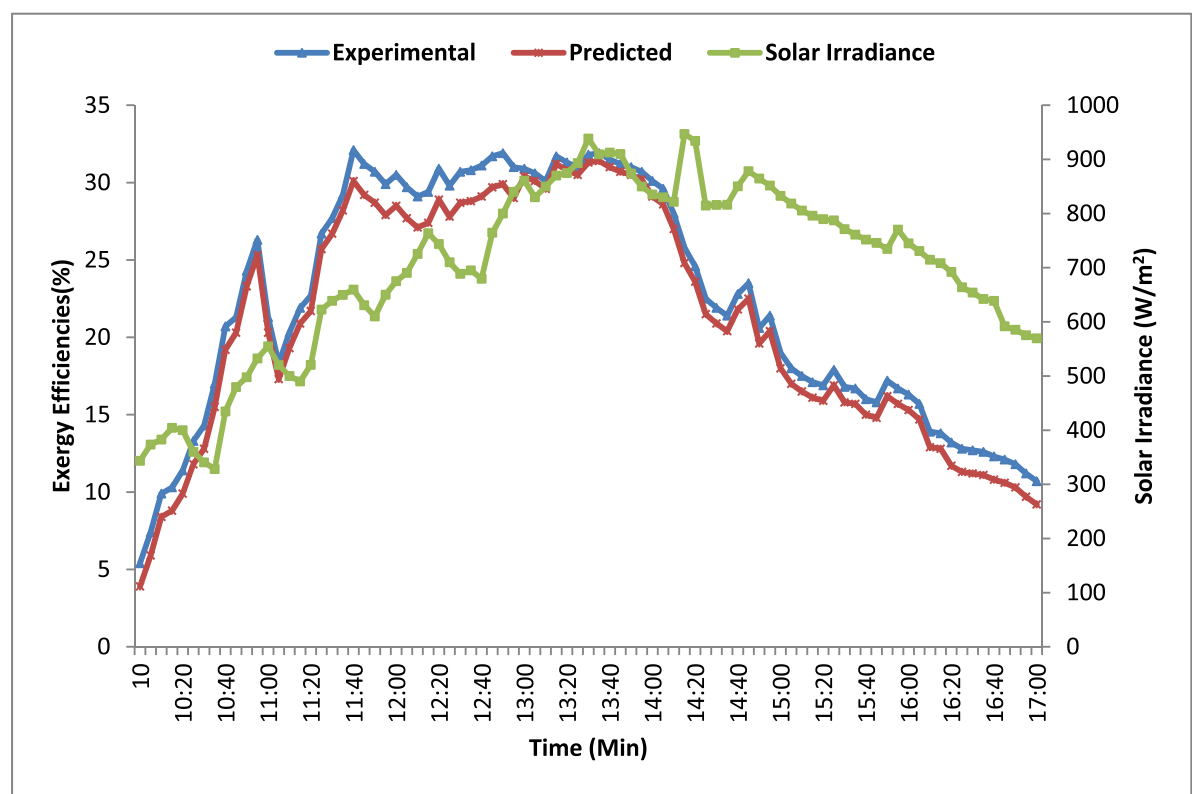

Fig. 19. Experimental and Predicted Energy Efficiency for Parabolic Dish cooker on 3rd December 2017.

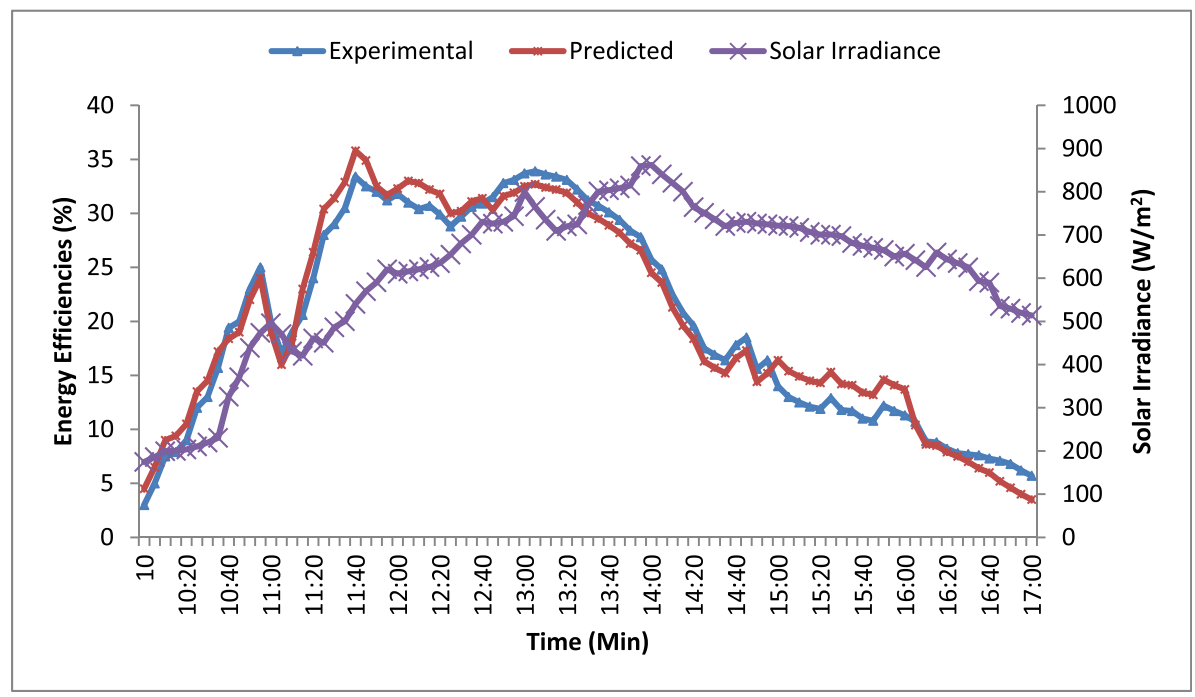

Fig. 20. Experimental and Predicted Energy Efficiency for Parabolic Dish cooker on 14th January 2018.

there was no significant difference between the experimental and predicted results for exergy and energy efficiencies of both cookers at $p>0.05$ showing that the mathematical model was valid. Also, the interactive plot obtained from the predicted energy and exergy efficiency shows that solar irradiance and time, as well as sensible temperature and time, have a great effect on the exergy and energy efficiency of the cooker.

\section{Conflicts of interest}

Authors declare that there is no conflict of interest whatsoever.

\section{Acknowledgement}

Authors wish to appreciate the efforts of Landmark University Technical staff for their immense contributions to the success of this work.

\section{Appendix A. Supplementary data}

Supplementary data to this article can be found online at https://doi.org/10.1016/j.renene.2019.04.028.

\section{References}

[1] U.C. Okonkwo, A.O. Onokwai, C.E. Okafor, Thermal performance of a developed solar box cooker for Awka metropolis, J. Eng. Appl. Sci. 12 (2018) (2018) $64-75$.

[2] I. Yahuza, Y.A. Rufai, L. Taninu, Design, construction and testing of parabolic solar, Oven. J. Appl. Mech. Eng. 2016 (2016).

[3] O. Dzioubinski, R. Chipman, Trends in consumption and production, in: Household Consumption. DESA Discussion Paper of the United Nations Department of Economic and Social Affairs, vol. 6, 1999, p. 21.

[4] U.C. Okonkwo, I.N. Ijioma, I.P. Onwuamaeze, Pollutants emissions of filling stations and their impact on the air quality, Int. J. Eng. 28 (6) (2015) 949-955.

[5] T. Gardner-Outlaw, R.E. Engelman, Forest Futures: Population, Consumption and Wood Resource, 2013. http://www.amazon.com/Forest-FuturesPopulation-Consumption-Resources/dp/1889735035. 
[6] World Health Organization (WHO), Fuel for Life, WHO, Geneva, 2006.

[7] A. Algifri, H. Al-Towaie, Efficient orientation impacts of box-type solar cooker on the cooker performance, Sol. Energy 70 (2) (2001) 165-170.

[8] C.E. Okafor, Feasibility study on the provision of solar energy in rural area using solar panel, J. Pure Appl. Sci. 9 (1) (2008) 111-120.

[9] N. Kumar, G. Vishwanath, A. Gupta, An exergy-based test protocol for truncated pyramid type solar box cooker, Energy 36 (2011) 5710-5715.

[10] A. Hereza, M. Ramadan, M. Khaled, Review on solar cooker systems: economic and environmental study for different Lebanese scenarios, Renew. Sustain. Energy Rev. 81 (2017) 421-432.

[11] C.O. Osueke, P. Uzendu, I.D. Ogbonna, Study and evaluation of solar energy variation in Nigeria, Int. J. Emerg. Technol. Adv. Eng. 3 (6) (2013) 501-505.

[12] R. Petala, Exergy analysis of the solar cylindrical-parabolic cooker, Solar Energy Elsevier 79 (2007) (2007) 221-233, elsevier.com/locate/rser.

[13] Z.F. Suhail, Determination of performance measuring parameters of an improved dual paraboloid solar cooker, Int. J. Photoenergy 2017 (2017) 12 http://doi.org/10.1155/2017.

[14] A. Harmim, M. Merzouk, M. Boukar, M. Amar, Mathematical modeling of a box-typesolar cooker employing an asymmetric compound parabolic concentrator, Sol. Energy 86 (2012), 1673-10.

[15] S.C. Kaushik, M.K. Gupta, Energy and exergy efficiency comparison of community-size and domestic-size paraboloidal solar cooker performance, Energy Sustain. Dev. 12 (2008) 60-64.

[16] H.H. Ozturk, Comparison of energy and exergy efficiency for solar box and parabolic cookers, J. Energy Eng. 133 (1) (2007) 53-62.

[17] A.K. Pandey, V.V. Tyagi, S.R. Park, S.K. Tyagi, Comparative experimental study of solar cookers using exergy analysis, J. Therm. Anal. Calorim. 109 (1) (2012) 425-431.

[18] I.L. Mohammed, Design and development of a parabolic solar thermal cooker, Int. J. Eng. Res. Appl. 3 (4) (2013) 1179-1186.

[19] U.C. Arunachala, J. Anuj, M. Sheikh, Design, fabrication and performance analysis of solar cooker for night cooking, in: 3rd World Conference on Applied Sciences, Engineering \& Technology 27-29 September 2014, Kathmandu, Nepal, 2014.

[20] K. Lovegrove, G. Burgess, J. Pye, A new $500 \mathrm{~m}^{2}$ paraboloidal dish solar concentrator, Sol. Energy 85 (2011) (2011) 620-626.

[21] I. Palavras, G.C. Bakos, Development of a low-cost dish solar concentrator and its application in Zeolite desorption, Renew. Energy 31 (15) (2006) 2422-2431.

[22] V. Thakkar, A. Doshi, A. Rana, Performance analysis methodology for parabolic dish solar concentrators for process heating using thermic fluid, IOSR J. Mech. Civ. Eng. 12 (1) (2015) 101-114.

[23] A. Ghani, et al., Development of design parameters for the concentrators of parabolic dish (PD) based concentrating solar power (CSP) under Malaysia environment, J. Appl. Sci. Agric. 9 (2014) (2014) 42-48.
[24] A.R. El-Quederni, M.B. Nasrallah, F. Aloui, Experimental study of a parabolic solar concentrator, Revue des Energies Reneuvelables 12 (2009) 395-404.

[25] ASHRAE -American Society of Heating Refrigeration and Air-Conditional Engineers, Applications Handbook (SI), ASHRAE, Atlanta, Ga, USA, 2008.

[26] P.R. Fraser, Stirling Dish System Performance Prediction Model, Doctoral Dissertation, University of Wisconsin-Madison, 2008.

[27] W.B. Stine, R.B. Driver, A Compendium of Solar Stiriling Technology. Report SAND 93-7026, Sandia National Laboratories, Albuquerque, NM, 1994.

[28] M.F. Ashby, Material and Process Selection Charts. The CES Edupack Resource Booklet 2.Granta Design, 2010. www.grantadesign.com.

[29] M.F. Ashby, Materials Selection in Mechanical Engineering, Elsevier Butterworth-Heinemann Linacre House, Jordan Hill, Oxford, 2005. www. elsevier.com.

[30] J. Aidan, Performance evaluation of a parabolic solar dish cooker in Yola Nigeria, IOSR J. Appl. Phys. (IOSR-JAP) 6 (5) (2014) 46-50. www.iosrjournals. org.

[31] O.E. Basil, Performance evaluation of parabolic solar cooker, Int. J. Eng. Technol. 3 (10) (2013).

[32] R. Petela, Exergy of undiluted thermal radiation, Sol. Energy 74 (2003) 469-488.

[33] F. Kreith, J. Kreider, Principles of Solar Engineering, Hemisphere McGraw-Hill, New York, 1978.

34] S.K. Tyagi, W. Wang, S.C. Kaushik, M.K. Singhal, S.R. Park, Exergy analysis an parametric study of concentrating type solar collectors, Int. J. Therm. Sci. 46 (2007) 1304-1310.

35] V. Krishnan, T. Balusamy, Simulation studies on concentrating type solar cookers. World Academy of science, engineering and technology, Int. J. Mech. Aerosp. Ind. Mechatron. Manuf. Eng. 9 (6) (2015) 1143-1147.

36] R. Akinoso, The development of a solar device for crop drying and cooking, LAUTECH, J. Eng. Technol. 5 (2009) 75-79.

[37] A.K. Aremu, R. Akinoso, Potential used of Box-type solar cooker in developing countries, J. Assoc. Prof. Eng. Trinidad Tobago 41 (2013) 11-17.

[38] M.S. Al-Soud, E. Abdallah, A. Akayleh, S. Abdallah, E.S. Hrayshat, A parabolic solar cooker with automatic two axes sun tracking system, Appl. Energy 87 (2) (2010) 463-470.

[39] Z. Guidara, M. Souissi, A. Morgenstern, A. Maale, Thermal performance of a solar box cooker with outer reflectors: numerical study and experimental investigation, Sol. Energy 158 (2017) 347-359.

[40] M. Ndiaga, H. Ali, Performance testing of a parabolic solar concentrator for solar cooking, J. Sol. Energy 138 (4) (2016), 15-1259.

41] A.O. Onokwai, Development of Solar Box and Parabolic Cookers, unpublished M.Eng Thesis, Nnamdi Azikiwe University, Awka, Nigeria, 2016.

[42] K. Saravanan, B. Janarthanan, Energy and exergy analysis of double exposure box-type solar cooker, IJIRSET 3 (6) (2014) 13104-13113. 